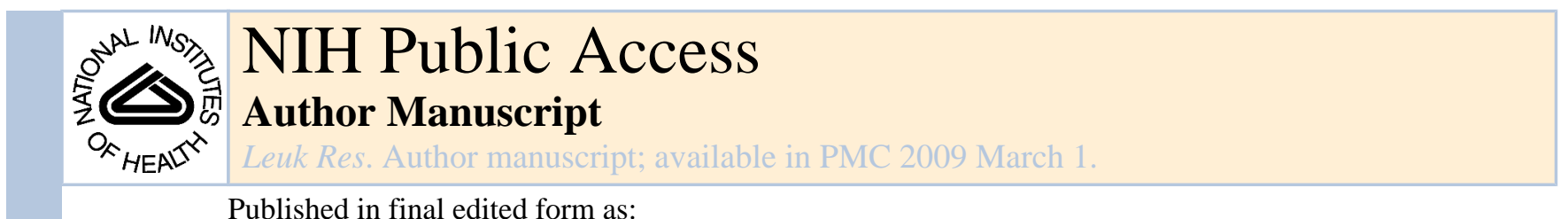

Published in final edited form as:

Leuk Res. 2008 March ; 32(3): 367-368.

\title{
Editorial for Leukemia Research
}

\section{Scott J. Samuelson, M.D. and Josef T. Prchal, M.D.}

In this issue of Leukemia Research, Veselovska et al., present an important study of pediatric essential thrombocythemia (ET) from the Czech Republic. Pediatric ET is a rare disorder that has not been well characterized. Thus, this study of 12 unrelated ET children and one individual with thrombocytosis and a family history of ET is especially valuable. When tested by allele specific PCR, detectable JAK2V617F mutation was not found in peripheral blood leukocytes, platelets or granulocytes and clonal hematopoiesis (detected by differential methylation of Xchromosome alleles) was only seen in one female of seven tested. Eight of the 12 ET patients demonstrated erythropoietin (Epo) hypersensitivity and endogenous erythroid colonies (EEC) were noted in 5 of the $12 \mathrm{ET}$ patients. The patient with thrombocytosis and a family history of ET also demonstrated rare EECs. The investigators performed genotyping on these EECs, with a small minority containing the $J A K 2 V 617 F$ mutation. Since $J A K 2 V 617 F$ mutation can by mitotic recombination undergo uniparenteral disomy ${ }^{1}$, a mixture of colonies bearing homozygous, heterozygous, and wild JAK2 alleles exist. It was suggested by Green's laboratory that homozygosity of some erythroid progenitors is seen exclusively in PV and not in $\mathrm{ET}^{2}$. However, these data have been challenged by multiple groups ${ }^{3}$ including ours ${ }^{4}$. As seen in Table 2 in the article, one ET child demonstrated one JAK2V617F homozygous EEC and one $J A K 2 V 617 F$ heterozygous EEC; one patient demonstrated a single heterozygous EEC; and the patient with thrombocytosis and a family history of ET had one homozygous EEC with two wild-type colonies. This article makes several other important observations and raises important questions for the future.

First, this is a relatively large clinical description of pediatric ET. It suggests an incidence of $1.1 /$ million children/year in the Czech Republic. No thrombosis or major bleeding was seen with a median follow up of 42 months, underlying an apparent benign course for this disorder during childhood.

Second, the presence of $J A K 2 V 617 F$ containing colonies may support other evolving literature suggesting that homozygosity of this mutation is not limited to polycythemia vera $(\mathrm{PV})^{3}$. This is in contrast to a frequently cited early study in patients with $\mathrm{PV}$ and $\mathrm{ET}^{2}$, although in that study two ET patients developed homozygous cells after polycythemic transformation. As has been demonstrated in $\mathrm{PV}^{5}$, the presence of the homozygous mutation in patients with ET may portend a more aggressive clinical course ${ }^{6}$. As the authors explore in their discussion, the detection of this mutation in EECs, but not in the circulating peripheral blood cells, suggests that the JAK2V617F containing subclones are rare in these patients and below the level of PCR detection. Additionally, or perhaps alternatively, the culture conditions without the addition of Epo may have favored the $J A K 2 V 617 F$ colonies. This would correlate with previously reported data from polycythemia vera showing that, in vitro, non-JAK2V617F cells are favored in the presence of $\mathrm{Epo}^{7}$, supported by the fact that no JAK2V617F colonies were seen in this study in Epo dependent BFU-E. Translation research efforts are ongoing to discover if supplemental

Publisher's Disclaimer: This is a PDF file of an unedited manuscript that has been accepted for publication. As a service to our customers we are providing this early version of the manuscript. The manuscript will undergo copyediting, typesetting, and review of the resulting proof before it is published in its final citable form. Please note that during the production process errors may be discovered which could affect the content, and all legal disclaimers that apply to the journal pertain. 
erythropoietin can reduce or eliminate the $J A K 2 V 617 F$ clone in patients with myeloproliferative disorders.

Third, the diagnostic and prognostic significance of EECs appearing in pediatric ET remains to be seen. As the authors discuss, existing data suggest a strong likelihood that adults who have EECs will eventually develop polycythemia vera ${ }^{8,9}$. The presence of EECs is frequently used as a clinical distinction in adults when assigning a diagnosis to a patient with an apparent myeloproliferative disorder. Whether or not this is true in children will have to be elucidated by further longitudinal studies.

In summary, we applaud the efforts of the authors to further our understanding of a rare disorder. It is clear that the development of diagnostic and prognostic algorithms in the myeloproliferative disorders, in both children and adults, will continue to be a fluid process as more knowledge is gained.

\section{Acknowledgements}

1. There are no conflicts of interest.

2. Supported by grants:1P01CA108671-O1A2 (NCI; Prchal) and R01HL50077-11 (NHLBI; PI Prchal).

3. Contributions: Dr. Samuelson wrote the original draft of the paper. Dr. Prchal did primary editing of the paper.

\section{References}

1. Kralovics R, Guan Y, Prchal JT. Acquired Uniparental Disomy of Chromosome 9p is a Frequent Stem Cell Defect in Polycythemia Vera. Experimental Hematology 2002;30:229-236. [PubMed: 11882360]

2. Scott LM, Scott MA, Campbell PJ, Green AR. Progenitors homozygous for the V617F mutation occur in most patients with polycythemia vera, but not essential thrombocythemia. Blood 2006;108:24352437. [PubMed: 16772604]

3. Pardanani A, Lasho TL, Finke C, et al. Extending JAK2V617F and MPLW515L Mutation Analysis to Single Hematopoietic Colonies and B- and T-lymphocytes. Stem Cells. 2007 Jun 1;Epub ahead of print

4. Nussenzveig RH, Swierczek SI, JJelinek J, Gaikwad A, Liu E, Verstovsek S, Prchal JF, Prchal JT. Polycythemia Vera is not Initiated by JAK2(V617F) Mutation. Experimental Hematology 2007;35:32-38. [PubMed: 17198871]

5. Vannucchi AM, Antonioli E, Guglielmelli P, et al. Influence of the JAK2V617F Mutational Load at Diagnosis on Major Clinical Aspects in Patients with Polycythemia Vera. Blood (ASH Annual Meeting Abstracts) 2006;108Abstract 5

6. Vannucchi AM, Antonioli E, Guglielmelli P, et al. Clinical profile; of homozygous JAK2V617F mutation in patients with polycythemia vera or essential thrombocythemia. Blood (1). 10.1182/ blood-2006-12-064287/prepublished online March 22, 2007

7. Gaikwad A, Nussenzveig R, Liu E, Gottshalk S, Chang K, Prchal JT. In vitro expansion of erythroid progenitors from polycythemia vera patients patients leads to decrease in JAK2 V617F allele. Experimental Hematology 2007 Apr;35(4):587-95. [PubMed: 17379069]

8. Shih LY, Lee CT. Identification of Masked Polycythemia Vera From Patients With Idiopathic Marked Thrombocytosis by Endogenous Erythroid Colony Assay. Blood 1994;83:744-748. [PubMed: 8298136]

9. Shih LY, Lee CT, Ou YC. Prediction of clinical course in patients with idiopathic erythrocytosis by endogenous erythroid colony assay but not by serum erythropoietin levels. Exp Hematol 1997;25:288292. [PubMed: 9131002] 